\title{
LEITURA E ESCRITA: CAMINHOS PARA O APRENDIZADO GEOGRÁFICO
}

\section{READING AND WRITING: PATHWAYS FOR GEOGRAPHICAL LEARNING}

\section{Mari Helen Weber Voss \\ Geografia Licenciatura - UNESC. E-mail: marihhelen@hotmail.com \\ Miriane Buss Roecker Geografia Licenciatura - UNESC. E-mail: miribroecker@hotmail.co m \\ Nilzo Ivo Ladwig PPGCA/UNESC E-mail: ladwig@unesc.net \\ Yasmine de Moura da Cunha Geografia/UNESC E-mail: ymc@unesc.net \\ Andréa Rabelo Marcelino Geografia/UNESC E-mail: armacelino@unesc.net}

\section{RESUMO}

Observações em sala de aula revelaram que o processo de ensino e aprendizagem está muito atrelado às aulas de repasse de informações sem resultados significativos. A partir desta constatação, surgiu o desígnio de resgatar metodologias básicas para a educação com o objetivo de propor ações de ensino e aprendizagem baseados na leitura e escrita na disciplina de geografia. Para atender o objetivo utilizou-se uma abordagem bibliográfica com orientações sobre a prática de leitura e escrita e como essas orientações podem colaborar no aprendizado do estudante, resultando na construção de um jornal escolar constituído por diversos gêneros jornalísticos que viabiliza a aplicação de metodologias e conceitos geográficos em sua construção. Durante o desenvolvimento do estudo percebeu-se a importância dessas metodologias na educação, contribuindo na formação de estudantes críticos e ativos em sociedade.

Palavras-chave: Geografia; Aprendizagem; Educação

\begin{abstract}
Observations in the classroom revealed that the teaching and learning process is very much linked to the classes of passing information without significant results. From this finding, the intention was to rescue basic methodologies for education with the aim of proposing teaching and learning actions based on reading and writing in the discipline of geography. In order to meet the objective, a bibliographical approach was adopted with guidelines on the practice of reading and writing and how these guidelines can collaborate in student learning, resulting in the construction of a school newspaper made up of several journalistic genres that enables the application of methodologies and concepts in its construction. During the development of the study it was noticed the importance of these methodologies in the education, contributing in the formation of critical and active students in society.
\end{abstract}

Keywords: Geography; Learning; Education 


\section{INTRODUÇÃO}

O ambiente escolar é cheio de surpresas e expectativas e ao ser inserido em sala de aula como docente, as percepções sobre este ambiente se divergem de quando se é estudante. Ambos estão ali como aprendizes, porém, os docentes necessitam mediar o conhecimento a ser transmitido sobre um tema específico. Para alcançar o conhecimento todas as aulas precisam de estudo, planejamento e metodologia que proporcione como resultados o ensino e aprendizagem dos estudantes.

O período de inserção escolar foi proporcionado pelo estágio supervisionado e pelo Programa Institucional de Bolsas de Iniciação à Docência - PIBID ${ }^{1}$. O estágio supervisionado é componente curricular do Curso de Geografia - Licenciatura, pela disciplina de Estágio Supervisionado do Ensino Fundamental e Médio, realizado em duas escolas públicas, uma delas da rede municipal de ensino que contabilizou uma carga horária de dezesseis (16) horas/aulas, e outra, da rede estadual que contabilizou dezoito (18) horas/aulas. O projeto do PIBID foi realizado em escolas públicas da rede municipal de ensino, contabilizou novecentos e sessenta (960) horas/aulas aplicadas no ensino fundamental II. Observou-se nesses períodos uma carência de metodologias pedagógicas voltadas à leitura e produção textual na área da geografia escolar. A observação se confirmou quando foi constatado em atividades de pesquisa, interpretações de textos, avaliações, redações, dentre outras atividades escolares, que parte dos estudantes apresentava defasagens na leitura e escrita, falta de senso crítico e argumentos sem fundamentos, conformando-se como cidadão acrítico. Por consequência, percebeu-se que a aula de geografia se resume no repasse de informações e com conceitos a serem decorados.

A leitura em sala de aula é uma prática na busca de novas informações e reflexões sobre diversos assuntos que podem ser abordados. Desenvolver ações que incentive o estudante a ler, contemplar análises textuais, constatar situações problemas, compreender a ideia de um texto e informações subtendidas, construir resumos, entre outros métodos. Contribui na interpretação dos significados das leituras, transformando-as em conhecimentos.

A partir do momento que o estudante passa a interpretar textos, associando significados às leituras, ele amplia seus conhecimentos e aprimora seu raciocínio, moldando pensamentos e modos de agir. Dessa forma, o estudante possui novos argumentos e fundamentos para desenvolver produções textuais. Essa prática desenvolve modos de se expressar sobre algum conhecimento obtido, e ainda, desenvolve o senso crítico, posicionando-se sobre o tema.

\footnotetext{
${ }^{1}$ Os projetos devem promover a iniciação do licenciando no ambiente escolar ainda na primeira metade do curso, visando estimular, desde o início de sua formação, a observação e a reflexão sobre a prática profissional no cotidiano das escolas públicas de educação básica. (CAPES, 2018).
} 
Após a contextualização desta situação, este trabalho tem como objetivo propor prática de ensino que aplique exercício de leitura e produção textual na disciplina de geografia, que possa beneficiar o processo de ensino aprendizagem.

\section{MARCO TEÓRICO}

O ensino de geografia, conforme Callai (1998), deve possibilitar que o estudante "[...] se perceba como participante do espaço que estuda, onde os fenômenos que ali ocorrem são resultados da vida e trabalho dos homens e estão inseridos num processo de desenvolvimento." (CALLAI, 1998 p. 56). Dessa forma, a disciplina de geografia precisa alcançar um ensino em que o estudante sintase como parte do estudo, e não como algo deslocado dos temas. Callai (1998) relata que é desafiador transformar a geografia em algo significativo relacionado à vida. Descarta a ideia de uma disciplina que faz uso de materiais e conceitos díspares da realidade, mas que possibilite a compreensão da interdependência entre o espaço natural e o ser humano, com suas constantes transformações, princípios e diretrizes.

Kaercher (2011) sugere que, para ensinar geografia de forma inovadora, o professor deve se dedicar mais ao estudo, trabalhar mais em grupo, dividir conhecimentos, angústias, sucessos e fracassos com os colegas da área da educação, obtendo referenciais teóricos e buscando novos apoios na construção de uma educação coerente. Pois, sabe-se que as metodologias aplicadas são ineficientes, uma troca de informações e até de dúvidas podem proporcionar crescimento. Para o estudante, apenas ouvir aulas não tem sido suficiente para que a nossa ciência não passe de conhecimentos vagos e com utilidades incompreensíveis. Essas práticas apáticas apenas descrevem o mundo. Para superá-las é necessário buscar novas bases, que propõem "alternativas de organização espacial que superem a simples descrição desinteressada e neutra do mundo" (KAERCHER, 2011, p. 81). Porém, é necessário buscar novas práticas, construindo alicerces que possam transformar a educação, tornando-a organizada e com um desenvolvimento natural.

Entre as metodologias bases, Kaercher (2011) aponta como indispensável "exercitar nossos alunos a escrever, ler e a dizer sua palavra em sala de aula e nas aulas de geografia." (KAERCHER, 2011, p. 81). Praticar essas ações objetiva “aprender a ler essa palavra escrita em que a cultura se diz e, dizendo-se criticamente, deixa de ser repetição intemporal [...]. Nesse sentido, alfabetizar-se não é aprender palavras, mas a dizer a sua palavra, criadora de cultura.” (FREIRE, 2005, p. 19). Com essas práticas, os estudantes podem se tornar mais cautelosos, reflexivos e discernir os conhecimentos.

Incentivar o estudante a ler, questionar e interpretar as leituras e expressar-se, memorizar os pensamentos, ideias, acontecimentos e outros fatores por meio da escrita, e ainda, exprimir-se através de palavras em sala de aula, pode auxiliar a ampliar conhecimentos, romper ideologias e crenças 
impostas, gerar novos significados e sentidos, buscar novos entendimentos, opiniões e ações na formação do caráter social, preparando-os para a vida em sociedade constantemente oscilante.

Cremos que inserir estas práticas no ensino e aprendizagem é um desafio, mas a geografia necessita formar pessoas leitoras e produtoras de textos escritos.

\subsection{PRÁTICA DE LEITURA}

O ensino de geografia está diretamente ligado aos diversos tipos de leituras presentes no cotidiano, como jornais, textos, outdoors, músicas, fotografias, dentre tantos outros meios de comunicação que podem nos informar sobre conceitos geográficos. Sabe-se que leitura é uma das principais metodologias a ser desenvolvida na área da educação, que, de acordo com Sachet (2017), é "um ato de conhecimento e transformação, pois ao ler, os indivíduos se transformam, e essa mudança acaba refletindo em sociedade.” (SACHET, 2017, p. 62). Cagliari (2007) ainda assegura que "de tudo o que a escola pode oferecer de bom aos alunos é a leitura, sem dúvida, o melhor, a grande herança da Educação." (CAGLIARI, 2007, p. 184).

$\mathrm{O}$ ato de ler pode ser considerado:

[...] uma decifração e uma decodificação. O leitor deverá em primeiro lugar decifrar a escrita, depois entender a linguagem encontrada, em seguida decodificar todas as implicações que o texto tem e, finalmente refletir sobre isso e formar o próprio conhecimento e opinião a respeito do que leu. (CAGLIARI, 2007, p. 150).

Desse modo, o leitor, em contato com os suportes de leitura, inicia um processo de descobrimento do que era desconhecido ou um aprimoramento de algo já descoberto. Para isto, necessita compreender a linguagem e o sentido da escrita com clareza. Só assim conseguirá atribuir interesse e interpretação da leitura, adquirindo conhecimentos.

Nesse sentido, Leffa (1996) também relata que "para compreender o ato de leitura temos que considerar então (a) o papel do leitor, (b) o papel do texto e (c) o processo de interação entre o leitor e o texto" (LEFFA, 1996, p. 17). Assim, Leffa (1996), descreve que o papel do leitor é gerar reconhecimento à leitura e o papel do texto é emitir informações e conhecimentos, porém, não basta fazer apenas a junção destes dois pontos, mas sim, o encontro do leitor e do texto, afirmando a interação entre ambos constituindo a compreensão. Entretanto, o leitor necessita:

[...] possuir, além das competências fundamentais para o ato da leitura, a intenção de ler. Essa intenção pode ser caracterizada como uma necessidade que precisa ser satisfeita, a busca de um equilíbrio interno ou a tentativa de colimação de um determinado objetivo em relação a um determinado texto. (LEFFA, 1996, p. 17). 
Considerando os fatores citados acima sobre a prática de leitura, constatamos que essa é uma metodologia complexa, que exige do estudante a interpretação do texto, a reflexão sobre a leitura e a percepção da intenção do texto, a partir das suas competências de leitura, para atingir como resultados desígnios sobre novos conjuntos de saberes. Ou seja, o leitor busca nas leituras suprir alguma necessidade, seja a resposta de questionamentos, incômodos, curiosidades, almejar conhecimento, realizar algum objetivo ou outros fatores. Mas, sempre deve haver alguma intenção no ato de ler.

De acordo com Cagliari (2007), essa prática tem por habitualidade ser guiada também por “[...] elementos culturais, ideológicos, filosóficos etc., do leitor” (CAGLIARI, 2007, p. 151). Em vista disso, a leitura de um mesmo texto, por pessoas diferentes, pode produzir interpretações heterogêneas, com base em seus conhecimentos de vida. Em consequência, cada um lê a seu modo, e é exatamente o que deve acontecer e a escola necessita respeitar isso. Pois a leitura de uma obra é sempre "[...] aberta, jamais fechada. Por mais que um escritor se esforce para restringir a leitura de sua obra a limites bem definidos e controláveis, jamais isso será possível em sua totalidade" (CAGLIARI, 2007, p. 151). Complementa Cagliari (2007) que o leitor interfere na leitura conforme suas particularidades.

É importante lembrar também dos tipos de leituras. Westermann (2003) confirma que a ação de ler é decorrente das buscas que o estudante deseja realizar. Em vista disso, "ele recorre ao jornal, à revista, ao texto da internet, ao atlas, ao gráfico, mas também ao filme, à entrevista. Por leitura, portanto, entende-se as mais diferentes possibilidades que lhe possam trazer respostas para suas indagações.” (WESTERMANN, 2003, p. 171). Considera-se que a “[...] leitura pode ser ouvida, vista ou falada". (CAGLIARI, 2007, p. 155). Dessa maneira, o ensino deve fomentar os diversos suportes de leitura e disponibilizar ao estudante essas vias, a fim de melhor desenvolver essa prática.

Instigar o interesse do estudante pela leitura não é algo tão fácil, para “aprender a ler requer que se ensine a ler" (SOLÉ, 1998, p. 173), a partir de propostas de ensino e aprendizagem. Entretanto, para ensinar a ler é importante a participação ativa dos estudantes e as suas contribuições de ideias para designar situações didáticas variadas, eficazes às diversidades encontradas em sala aula, possibilitando práticas heterogêneas e construtivas. Solé (1998) segue dizendo que "[...] ensinar a ler é compartilhar. Compartilhar objetivos, compartilhar tarefas, compartilhar os significados construídos em torno delas." (SOLÉ, 1998 p. 173). Este compartilhamento proporciona uma atividade de troca de saberes, entre docente e estudantes, desenvolvendo assim:

[...] atividades em que os alunos tenham que perguntar, prever, recapitular para os colegas, opinar, resumir, comparar suas opiniões com relação ao que leram, tudo isso fomenta uma leitura inteligente e crítica, na qual o leitor vê a si mesmo como protagonista do processo de construção de significados. (SOLÉ, 1998, p. 173). 
Logo, Solé (1998) certifica que a leitura deve ser desenvolvida em equipe nos diferentes processos e estágios de ensino.

Diante destas atribuições, a escola poderá formar bons leitores, propiciando autonomia ao indivíduo em sociedade, considerando que a leitura o acompanhará durante toda a sua vida.

\subsection{PRODUÇÃO TEXTUAL}

A leitura e a escrita são práticas indissociáveis. Por essa razão, a escrita também precisa estar presente nas metodologias escolares, auxiliando na formação de autores e sujeitos com habilidades, na construção de significados e sentidos aos variados temas expostos no ambiente escolar e sociedade. Koch e Elias (2009) abordam que na contemporaneidade somos habituados a escrever textos em diferentes situações do cotidiano. Portanto, "[...] a escrita é onipresente em nossa vida." (KOCH; ELIAS, 2009, p. 31).

Conforme Pasquier e Dolz (1996), a produção de um texto é difícil e requer diferentes habilidades, carecendo de exercícios constantes. Todavia, todo estudante é capaz de produzir um texto coesivo em relação aos temas estudados, se obtiverem as orientações de ensino e aprendizagem efetiva.

Sabendo que o ato de escrever, segundo Jolibert e Jacob (2006):

é produzir mensagens reais, com intencionalidade e destinatários reais. [...] Escrever é produzir textos ou, melhor, tipos de texto, em função das próprias necessidades e projetos: cartas, cartazes, receitas, notícias, histórias, poemas, etc. Não se trata de produzir frases soltas ou parágrafos isolados que depois teriam que ser colocados a outros fragmentos para constituir um texto completo. (JOLIBERT; JACOB, 2006, p.191).

Jolibert e Jacob (2006) expõem que escrever é um procedimento gradativo, que exige de diferentes etapas, retificando as vertentes estruturais. Após o texto pronto, também é necessária a reescrita, para uma melhora progressiva, até obter uma versão final do texto. $\mathrm{O}$ aprendizado da produção textual só é obtido na elaboração de diversos textos comunicativos e sinceros condizentes com a realidade. Nesse sentido,

[...] as crianças devem tomar consciência, por meio do vivenciado, da utilidade de escrever um texto: um texto comunica alguma coisa, narra alguma coisa, explica, informa, incentiva, entretém, etc. Também deve ter a oportunidade de experimentar o poder e prazer proporcionado pelo domínio adequado da produção de um texto, que pode convidar a um evento, expressar sentimentos, sonhos ou opiniões, solicitar alguma coisa, exigir o cumprimento de uma regra ou lei, argumentar para atingir um objetivo, divertir ou comover, entre outras coisas. (JOLIBERT; JACOB, 2006, p. 192). 
Pasquier e Dolz (1996) complementam que o estudante deve obter entendimento da diversidade textual, para desenvolver textos comunicativos. "E, para isso, terá de inspirar-se em ou ter como referência outros textos sociais em uso." (PASQUIER; DOLZ, 1996, p. 2). Por esses motivos, a utilização de recursos didáticos deve ser conhecida pelos docentes, de forma que "[...] tenha ideias claras sobre o ensino da produção escrita, de maneira que não se perca em atividades entediantes, repetitivas, desnecessárias e, sobretudo, pouco eficazes.” (PASQUIER; DOLZ, 1996, p. $1)$.

\section{O JORNAL COMO PROPOSTA METODOLÓGICA DE LEITURA E PRODUÇÃO TEXTUAL}

A leitura e a produção textual são metodologias amplas, que podem proporcionar planejamentos de diversas atividades a serem desenvolvidas no ambiente escolar. Nessa perspectiva, a proposta aqui apresentada é resultado de inquietações e buscas por aulas dinâmicas, com significados para os estudantes.

A construção de um jornal, segundo Pavani, Junquer e Cortez (2007), necessita compor-se de discussões de temáticas e assuntos relevantes aos elementos ou problemas sociais, propondo a formação de opiniões críticas e interpretações diferentes sobre acontecimentos e fatos dos diversos elementos da sociedade. Ou seja, “[...] a produção de um jornal é o registro de opiniões de um grupo responsável pelo jornal.” (PAVANI; JUNQUER; CORTEZ, 2007, p. 97).

Sabendo-se que o jornal é constituído por diversos gêneros jornalísticos, viabiliza a aplicação de diversas metodologias para sua construção. Dentre elas podem ser desenvolvidas, de acordo com Faria (1989), uma notícia, uma reportagem, enquetes e entrevistas, reportagem fotográfica, a legenda e o editorial. Pavani, Junquer e Cortez (2007), apresentam outros gêneros, como a construção de um artigo, caderno especial e edição especial, resenha, coluna jornalística e as histórias em quadrinhos.

\subsection{AÇÕES METODOLÓGICAS NECESSÁRIAS PARA ELABORAÇÃO DO JORNAL}

Para elaborar uma notícia, descreve Faria (1989) que é necessário que o estudante realize uma pesquisa, uma seleção de referências, dados e fatores importantes, em diversos suportes de leitura ou em uma entrevista. E a partir das interpretações dos elementos coletados, descrever sobre o acontecimento em forma de uma informação exata e imediata. A reportagem, segundo Faria (1989) se assemelha à construção da notícia. No entanto, exige maior objetividade e aprofundamento no levantamento de dados, como dirigir-se ao lugar dos fatos, para maior conhecimento das informações e a oportunidade de coletar fotografias. A reportagem é essencialmente expositiva, o autor necessita expor o sentido da informação. 
Outras metodologias que podem compor um jornal são as enquetes ou entrevistas. Faria (1989) relata que as enquetes são feitas com base em uma entrevista em grupos, reunindo diversas opiniões. E a "entrevista é a matéria jornalística apresentada sob a forma de pergunta e resposta" (FARIA, 1989). A entrevista pode apresentar, segundo Faria (1989), uma notícia, que busca no entrevistado informações sobre fatores que ocasionarão a notícia. Ou uma entrevista de opinião, que informa a opinião do entrevistado conforme o assunto abordado. E, ainda, uma entrevista para a construção de uma biografia do entrevistado, expondo suas ideias, gostos, profissão e outros aspectos pessoais.

Faria (1989) relata que a reportagem fotográfica é a metodologia que mais gera entusiasmo nos estudantes. A primeira sugestão é que os estudantes realizem as fotografias e redijam suas informações. Ou, pode-se buscar por fotos em suportes já impressos ou digitais, para auxiliar nessa atividade, visando à criação de uma reportagem a partir da interpretação da imagem, analisando as paisagens, acontecimentos, épocas, gestos, dentre outros aspectos solidificados no momento da foto. A legenda é um breve e claro texto que descreve o tema da fotografia, algo criativo e que chame o leitor.

O editorial é a metodologia, conforme Faria (1989), mais complexa, pois expõe as ideias, argumentos e críticas do autor, que devem se posicionar sobre algum acontecimento, fato ou evento, que estão em destaque em sociedade. Esse método consiste na criação de uma dissertação/redação, onde o autor do texto se expressa de forma escrita sobre diversas áreas de conhecimento.

Pavani, Junquer e Cortez (2007) descrevem que o artigo é produção textual de opinião sobre determinado tema. $\mathrm{O}$ artigo não pretende divulgar um acontecimento, mas emitir a opinião sobre um assunto já conhecido. Esse tipo de escrita exercita a criticidade e a capacidade argumentativa, convencendo ou provocando reflexões para o leitor.

O caderno especial e edição especial objetivam escrever, conforme Pavani, Junquer e Cortez (2007), sobre “[...] um tema específico e ocasional, como por exemplo, o aniversário da cidade, a Copa do Mundo, os Jogos Pan-americanos etc.” (PAVINI; JUNQUER; CORTEZ, 2007, p. 53), noticiando sobre a relevância destes acontecimentos, ou ainda, explicando melhor a ocorrência dessas datas.

A resenha “[...] são exposições e análises de publicações ou textos que têm por finalidade fornecer informações sobre o conteúdo e o seu valor para orientar o leitor." (PAVINI; JUNQUER; CORTEZ, 2007, p. 53), podendo ser uma crítica ou indicação informativa de livros, revistas, filmes e outros.

A história em quadrinhos também é uma boa metodologia, pois apresenta “[...] uma forma de expressão artística feita em sequência [...].” (PAVINI; JUNQUER; CORTEZ, 2007 p. 62). Conforme 
Pavani, Junquer e Cortez (2007), pode abordar diversos assuntos e estilos, contendo uma narrativa, desenhos, sobreposição de imagens com textos, ideias, ações e emoções de um personagem, dentre outros métodos. Retratando temas de forma figurativa, ou seja, são representações feita por meio de simbologias seguindo a cronologia dos fatores a serem relatados.

O desenvolvimento destas ações metodológicas pode resultar na composição de um jornal, que, de acordo com Pavani, Junquer e Cortez (2007), pode ser trabalhado com uma ou mais classes de ensino fundamental ou médio, organizado por docentes, estudantes e outros funcionários. Sua divulgação pode ocorrer no ambiente escolar e também fora dele. A impressão do jornal também é um fator importante. Dependendo das condições da escola, o jornal pode ser redigido e impresso ou manuscrito. Ou ainda, sua reprodução pode ser via computador e disponibilizado em alguma plataforma digital.

\section{CONSIDERAÇÕES FINAIS}

O desenvolvimento da pesquisa centrou-se na busca por abordagens metodológicas que contribuam para o ensino e aprendizagem por meio do exercício da leitura e escrita. $\mathrm{O}$ estudo demonstra que o exercício da leitura e produção textual poderá contribuir para a formação de estudantes mais conscientes, portando-se como um cidadão ativo em face às transformações e entendimento do cotidiano.

É importante observar o ambiente escolar para conhecer as necessidades de aprendizagem dos estudantes, para que se possam desenvolver práticas que auxiliem os estudantes a suprir suas carências no ensino e aprendizagem.

Diante do problema constatado, a educação atual necessita resgatar as práticas de leitura e escrita, propondo um ensino que estimule o estudante a buscar conhecimentos científicos, a partir de pesquisas e análises nos diversos suportes disponíveis, a formar sua sapiência, capaz de expressar-se sobre os novos conhecimentos, transformar seu senso crítico e ressignificar-se como cidadãos. Para adquirir também, uma autonomia intelectual.

Por fim, as aulas de geografia deixam de ser um repasse de informações e conceitos, visto que, o estudante se torna mais ativo em sala de aula, na busca pelo ensino e aprendizagem.

A construção de um jornal escolar ou um jornal geográfico propõe diversas ações metodológicas na disciplina de geografia ou como proposta interdisciplinar. A área da leitura possibilita a compreensão de textos de vários suportes e gêneros, a análise de paisagens, imagens, gestos e ações, ou seja, a leitura de diversos elementos presentes no dia-a-dia. E a escrita proporciona desenvolver uma técnica de expressão, memorizando e materializando o conhecimento, por meio dos signos gráficos ou desenhos ilustrativos. 
O jornal como proposta metodológica aplica-se para findar e aperfeiçoar os estudos e exercícios sobre os conceitos referentes à disciplina. A construção deste material não é veiculada apenas para o professor ler e avaliar, é um meio de comunicação que pretende disponibilizar informações para uma coletividade, seja no âmbito escolar ou comunidades.

Vale lembrar que todas as metodologias devem ser mediadas pelo docente, orientando os estudantes sobre os conteúdos, fornecendo indicações e estratégias de leituras, esclarecendo os modelos de textos e todos os componentes das metodologias. Deixar claro o objetivo de cada atividade e participar da construção do conhecimento, proporciona sempre um ambiente de troca de experiência.

O ambiente escolar impõe trabalho em ritmo acelerado, por vezes sem reflexão e integração entre docentes e estudantes, dificultando atividades lineares. Mas, este ambiente acelerado não deve impossibilitar o docente em pensar metodologias que possam melhorar o ritmo e as condições da educação. Nessa perspectiva, foi elaborado o trabalho que aponta como conclusão que o docente precisa refletir sobre práticas escolares de acordo com as necessidades dos estudantes e com novas de ações metodológicas a serem desenvolvidas em sala de aula.

\section{REFERÊNCIAS}

CAGLIARI, Luiz Carlos. Alfabetização e linguística. 10. ed. São Paulo: Editora Scipione, 2007. $191 \mathrm{p}$.

CALLAI, Helena Copetti. O ensino de Geografia: Recortes espaciais para análise. In: CASTROGIOVANNI, Antonio Carlos; CALLAI, Helena Copetti; SCHAFFER, Neiva Otero; KAERCHER, Nestor André (Org.). Geografia em sala de aula: Práticas e reflexões. Porto Alegre: Associação dos Geógrafos Brasileiros, 1998. p. 55-60.

CAPES. Pibid - Programa Institucional de Bolsa de Iniciação à Docência. Disponível em: <http://www.capes.gov.br/educacao-basica/capespibid/pibid>. Acesso em: 04 jul. 2018.

FARIA, Maria Alice. O jornal na sala de aula. São Paulo: Contexto, 1989. 128 p.

FREIRE, Paulo. Pedagogia do oprimido. 43. ed. Rio de Janeiro: Editora Paz e Terra S/A, 2005. $213 \mathrm{p}$.

JOLIBERT, Josette; JACOB, Jeannette. Além dos muros da escola: A escrita como ponte entre alunos e comunidade. Porto Alegre: Artmed, 2006. 245 p.

KAERCHER, Nestor André. Ler e escrever a geografia para dizer a sua palavra e construir o seu espaço. In: NEVES, Iara Conceição Bitencourt; SOUZA, Jusamara Vieira; SCHAFFER, Neiva Otero; GUEDES, Paulo Coimbra; KLUSENER, Renita (Org.). Ler e escrever: Compromisso de todas as áreas. Porto Alegre: Editora da UFRGS, 2011. p. 77-90.

KOCH, Ingedore Villaça; ELIAS, Vanda Maria. Ler e escrever: Estratégias de Produção textual. 2. ed. São Paulo: Contexto, 2015. 220 p.

LEFFA, Vilson. Aspectos da Leitura. Porto Alegre: Sagra - Luzzatto, 1996. 98 p.

SACHET, Claudia Milanez. Concepções de leitura de professores alfabetizadores no contexto de um município do Extremo Sul Catarinense. 2017. 192 f. Dissertação (Mestrado) - Curso de 
Programa de Pós-graduação em Educação, Universidade do Extremo Sul Catarinense, Criciúma, 2017.

SOLÉ, Isabel. Estratégias de leitura. 6. ed. Porto Alegre: Artmed, 1998. 194 p.

PASQUIER, Auguste; DOLZ, Joaquim. Um decálogo para ensinar a escrever. 1996. Disponível em: 〈https://www.escrevendoofuturo.org.br/arquivos/4928/um-decalogo-dolz-pasquier.pdf>. Acesso em: 16 jun. 2018.

PAVANI, Cecília; JUNQUER, Ângela; CORTEZ, Elizena. Jornal: Uma abertura para a educação. Campinas - SP: Papirus, 2007. 115 p.

WESTERMANN, Liége. Mudar o professor, mudar a escola: uma experiência com projetos em língua portuguesa. In: REGO, Nelson; AIGNER, Carlos; PIRES, Cláudia; LINDAU, Heloísa (Org.). Um pouco do mundo cabe em suas mãos: Geografizando em educação o local e o global. Porto Alegre: Editora da UFRGS, 2003. p. 169-175. 